\title{
Publishing Short-Cuts and Their Potential Career Impact
}

\author{
Suzanne E. Morris
}

Received: 30 May 2013/Revised: 12 July 2013/Accepted: 16 July 2013/Published online: 27 July 2013

(c) Springer International Publishing AG 2013

\begin{abstract}
One essential element to a successful research career is your ability to produce quality, peer-reviewed publications. In the process of learning how to do research and write publications based on your findings, most doctoral students and early career researchers will be faced with decisions that may impact on their burgeoning careers. You may come across many freeways and roadblocks on your research journey and the temptation to take short-cuts to 'get that paper published' is attractive to some. To illustrate the importance of basic ethical considerations when publishing, this article explores the story of Cindy and will raise your awareness of publishing short-cuts and their potential impact on your career. This article will also provide you with suggested places to seek guidance to develop your ethical responsibility as a researcher.
\end{abstract}

Keywords Doctoral student - Early career researcher - Publication ethics - Research integrity

\section{Cindy's Story}

Cindy is an early career researcher at Down Under University. In early 2011, Cindy started to prepare a grant application that if successful would provide her with a salary and operating costs for the next 5 years. Getting this grant would provide Cindy with an easy path to obtaining tenure at Down Under University. Cindy knew that a good grant application took time to develop so started working on her application now for submission in March 2012.

S. E. Morris $(\bowtie)$

Sustainable Minerals Institute, The University of Queensland,

Brisbane, QLD 4072, Australia

e-mail: suzanne.morris@uq.edu.au
Cindy was required to provide a detailed description of her publishing track record and in the course of preparing her application, Cindy realised she had not published any papers since her $\mathrm{PhD}$ (and that was 2 years ago). In an effort to improve her track record before lodging her grant application, Cindy prepared a few papers from work she undertook during her $\mathrm{PhD}$. She prepared the papers by copying and pasting a substantial amount of the literature and results directly from her $\mathrm{PhD}$ thesis. She submitted the papers to several different journals, with one of her papers submitted to and subsequently published by The Journal of Long Life in February 2012. The Journal of Long Life is the leading international journal in Cindy's discipline.

Two months ago, Robert, the editor of The Journal of Long Life, received a complaint from an aggrieved author Susan, alleging that Cindy's article published in the February 2012 edition of The Journal of Long Life contained identical data to Susan's 2008 paper published in Live Long.

After seeking more information from Sheila and asking for a copy of her 2008 article showing the claimed identical data, Robert wrote to Cindy asking her to explain the data similarities alleged by Susan. This is Cindy's response:

Did I really do that? Oh, that's right... I was in the process of rearranging the copied/pasted text into something that resembled an article when my Head of Department asked me to drop everything and teach an intensive 2-month undergraduate course. When I finally got back to finishing the paper, I was in such a hurry to submit it, I forgot to check that I had included the right data and text and forget to check whether I had appropriately referenced other people's work. As it now turns out, I included Susan's data instead of my own in the February 2012 paper. 
After reading her response and believing there could be more to the story, Robert referred the matter to Cindy's employer, Down Under University, for further investigation. Robert also published an expression of concern regarding Cindy's article in The Journal of Long Life.

After an investigation by Down Under University, Cindy was formally disciplined for poor academic practice and research misconduct (plagiarism) and was proved to have cut and paste text and data from Susan's 2008 article. Down Under University also informed Robert of the outcome of the investigation and Robert retracted Cindy's article from The Journal of Long Life.

\section{Unpacking Cindy's Story}

Cindy was under pressure to publish. With doctoral students and early career researchers (ECRs) competing in a tough market for jobs, grants and scholarships, hiring committees and funding agencies often use publication experience to separate more and less desirable applicants $[1,2]$. Cindy was aware of this and knew that a lack of papers in the past 2 years was a major disadvantage to her grant application. However, in a rush to boost her publication track record, Cindy compromised the integrity of her work and claimed another researcher's findings as her own, that is, she committed plagiarism.

While academic honesty and avoiding plagiarism are fundamental principles of the responsible conduct of research, the definition of plagiarism differs across organisations. The US Office of Research Integrity (ORI) has adopted this working definition of plagiarism: 'plagiarism includes both the theft or misappropriation of intellectual property and the substantial unattributed textual copying of another's work' [3]. Other definitions are more detailed: 'plagiarism is the act of misrepresenting as one's own original work the ideas, interpretations, words or creative works of another. These include published and unpublished documents, designs, music, sounds, images, photographs, computer codes and ideas gained through working in a group. These ideas, interpretations, words or works may be found in print and/or electronic media' [4].

While the actions that constitute research misconduct vary across countries, in all jurisdictions, research misconduct includes 'fabrication, falsification, or plagiarism in proposing, performing, or reviewing research, or in reporting research results' [5]. The term 'research misconduct' rather than 'research fraud' is typically used to describe these researcher indiscretions as 'fraud indicates some kind of deception, while not all kinds of research misconduct, such as tampering with experiments-are deceptions' [6]. However, for those actions that are considered fraudulent, the penalties imposed can include jail time. For example, Eric Poehlman was the first US scientist sentenced to jail for 'falsifying and fabricating research data in numerous federal grant applications and in academic articles' [7], and Steven Eaton was the first UK scientist sentenced to jail for falsifying research data in experiments on anti-cancer drugs [8].

In addition to varied definitions of research misconduct, procedures for managing allegations of research misconduct vary both across countries and across institutions within the one country. In their report from the 2007 Workshop on Best Practices for Ensuring Scientific Integrity and Preventing Misconduct, the Organisation for Economic Co-operation and Development (OECD) acknowledged that 'there is not an allembracing, one-size-fits-all global solution, due to the considerable diversity among countries in such variables as the overall structure of the science system, the roles of public and private institutions, the status of researchers (e.g. whether they are public servants), the legal system, and historical traditions and customs' [9]. As research collaborations are increasingly conducted on a global scale, the OECD has developed a practical guide for institutions to help manage allegations of research misconduct in international collaborations [10].

Whether by error or intent, the plagiarism committed by Cindy had a significant impact on her credibility. Cindy's peers and colleagues may have subsequently questioned the accuracy of her other papers and maybe even her thesis. Furthermore, if Cindy's research was funded, Down Under University may have had to disclose her research misconduct to the funding body. For example, if Cindy was funded by a National Science Foundation (NSF) grant, the NSF could request actions or impose sanctions on Cindy or Down Under University such as: the requirement to correct the research record; totally or partially suspend, or terminate an active award; or prohibit Cindy's participation as an NSF reviewer, advisor or consultant for a specified period [11].

With the internet playing a major role in communicating research outcomes, it is also a common place for researcher indiscretions to be discussed. The digital footprint from Cindy's action would linger long after the mistake was uncovered. If Cindy's story was real, then it is likely that news of her article's retraction would feature on the web site 'Retraction Watch'. In writing this paper, I came across a retracted article that by coincidence had similarity to Cindy's case. In that retracted paper, the authors constructed a paper by copying a number of passages from another paper and claiming it as their own [12]. After the initial posting about the article's retraction, observers have made their own comments about the article and questioned the credibility of other work by the authors.

In addition to the researcher, journal editors play an important role in the dissemination of research. Journal editors should be accountable for everything published in their journal. Moreover, they have a responsibility to 
maintain the integrity of the research they publish and have a duty to act if they suspect misconduct or if an allegation of misconduct is brought to them [13, 14].

After an initial enquiry into Susan's allegations and a questionable response from Cindy, Robert published an expression of concern regarding Cindy's 2012 paper in The Journal of Long Life. 'An expression of concern is a publication notice that is generally made by an editor to draw attention to possible problems, but it does not go so far as to retract or correct an article' [15]. Robert had concerns about the reliability of Cindy's article but did not have enough information to retract the article after his initial enquiry, so he published an expression of concern and referred the matter to Down Under University to investigate. The recommended process for an editor to follow in such a circumstance is more fully described by the Committee on Publication Ethics (COPE) [16].

'COPE is a forum for editors and publishers of peerreviewed journals to discuss all aspects of publication ethics. It also advises editors on how to handle cases of research and publication misconduct' [17]. COPE also has useful resource for authors who would like to know more about how editors and publishers manage ethical considerations in publishing. The COPE flowcharts, which have been designed to help editors follow COPE's Code of Conduct and implement COPE advice when faced with cases of suspected misconduct [18], cover a range of publication ethics topics including managing authorship changes, undisclosed conflicts of interest, concerns about peer review and ethical problems with the research reported in submitted manuscripts.

When the results of the Down Under University were known and Cindy was found to have plagiarized text and data from Susan's 2008 article, Robert retracted the article. A retraction, which can be issued by an author, editor, publisher or other authorized agent (e.g. legal counsel and representatives from the institution or organisation where the work was produced), is a formal note in a journal that a previously published article has been removed from the literature due to a 'pervasive error, non-reproducible research, scientific misconduct, or duplicate publication' [15]. In addition to retracting an article, a journal editor may impose sanctions on the 'guilty' author/s for a period of time when misconduct has been confirmed [15]. If Robert imposed sanctions on Cindy, it would restrict her ability to publish in her discipline's leading journal.

\section{Concluding Remarks}

As highlighted several times though this article, researchers, particularly doctoral students and ECRs are under pressure to publish. However, these career pressures are 'no excuse for carelessness or misconduct [as] integrity is a cornerstone of science' [19].

'Good publication practices do not develop by chance, and will become established only if they are actively promoted' [14]. As discussed in [20], supervisors and institutions have a responsibility to promote the development and growth of students so they have an understanding of 'ethical and social responsibility as a researcher and member of the discipline or field of study' [20]. Universities, through their libraries or student support services typically offer guidance on academic writing and avoiding plagiarism (e.g. [21]). Training in the responsible conduct of research, which is a requirement of some funding agencies such as the NSF [22] and National Institutes of Health [23], is typically offered through the university research office (e.g. [24]). There are many free online resources now available to help you develop your ethical responsibility as a researcher, so if you need more support than that provided by your institution, you could explore the information provided by relevant journals and publishers in your discipline, COPE and ORI, to name a few.

From doctoral students to senior professors, all researchers have a responsibility to conduct their research and report their findings with integrity. Researchers should be aware of institutional and funding body policies in relation to responsible research, and understand what expectations are being placed on them by their professional societies and journals in which they wish to publish their research. To act without knowledge of these 'rules' or to disrespect them all together can 'impair one's reputation and livelihood' [25]. Such was the case in Cindy's story.

Acknowledgments The author is currently employed by The University of Queensland, Australia, and is the COPE Ombudsman. Cindy's fictitious story was first shared as The Down Under Blunder with participants of the COPE Asia Pacific Seminar, 15 February 2013, Melbourne, Australia.

\section{References}

1. Paré A (2010) Slow the presses: concerns about premature publication. In: Aitchison C, Kamler B, Lee A (eds) Publishing pedagogies for the doctorate and beyond. Routledge, Oxon, pp 30-46

2. Morris SE (2011) Taking the angst out of authorship dilemmas. In: Kumar V, Lee A (eds) Doctoral education in international context: connecting local, regional and global perspectives. Universiti Putra Malaysia PressSerdang, Serdang, pp 193-213

3. Office of Research Integrity (ORI) (2013) ORI policy on plagiarism. http://ori.hhs.gov/ori-policy-plagiarism. Accessed 11 July 2013

4. The University of Queensland (UQ) (2011) PPL 4.20.05 Research misconduct. http://ppl.app.uq.edu.au/content/4.20.05-researchmisconduct. Accessed 11 July 2013

5. Office of Research Integrity (ORI) (2011) Federal research misconduct policy. http://ori.hhs.gov/federal-research-misconductpolicy. Accessed 12 July 2013 
6. US Department of Health and Human Services, Public Health Service (1995) Integrity and misconduct in research report of the commission on research integrity. US Government Printing Office, Washington DC

7. Office of Research Integrity (ORI) (2005) Press release-Dr. Eric T. Poehlman. http://ori.hhs.gov/press-release-poehlman. Accessed 12 July 2013

8. BBC (2013) Scientist Steven Eaton jailed for falsifying drug test results. http://www.bbc.co.uk/news/uk-scotland-edinburgh-eastfife-22186220\#?utm_source=twitterfeed\&utm_medium=twitter. Accessed 12 July 2013

9. Organisation for Economic Co-operation and Development Global Science Forum (OECD) (2007) Best practices for ensuring scientific integrity and preventing misconduct. www.oecd. org/sti/sci-tech/40188303.pdf. Accessed 12 July 2013

10. Organisation for Economic Co-Operation and Development Global Science Forum (OECD) (2008) Co-ordinating committee for facilitating international research misconduct investigations. www.oecd.org/sti/sci-tech/42713295.pdf. Accessed 12 July 2013

11. National Science Foundation (NSF) (2002) 45 Code of federal regulations (CFR) Part 689-research misconduct. In: 67 federal register (FR) 11937, Mar 18 2002. www.nsf.gov/oig/resmisreg. pdf. Accessed 27 May 2013

12. Retraction Watch (2013) Plagiarism: It's just an "approach" to writing papers, right? http://retractionwatch.wordpress.com/2013/ 05/06/plagiarism-its-just-an-approach-to-writing-papers-right/. Accessed 24 May 2013

13. Committee on Publication Ethics (COPE) (2011) Code of conduct and best practice guidelines for journal editors. http://publicationethics.org/ files/Code_of_conduct_for_journal_editors_Mar11.pdf. Accessed 14 April 2013

14. Graf C, Wager E, Bowman A, Fiack S, Scott-Lichter D, Robinson A (2007) Best practice guidelines on publication ethics: a publisher's perspective. Int J Clin Pract 61(S152):1-26. doi:10.1111/ j.1742-1241.2006.01230.x

15. Council of Science Editors (CSE) (2013) CSE's White paper on promoting integrity in scientific journal publications: 3.5.1 definitions. http://www.councilscienceeditors.org/i4a/pages/index. cfm?pageid=3647. Accessed 24 May 2013
16. Committee on Publication Ethics (COPE) (2012) What to do if you suspect plagiarism (b) suspected plagiarism in a published article. http://publicationethics.org/files/u2/02B_Plagiarism_ Published.pdf. Accessed 21 May 2013

17. Committee on Publication Ethics (COPE) (2013a) Promoting integrity in research publication. http://publicationethics.org. Accessed 27 May 2013

18. Committee on Publication Ethics (COPE) (2013b) Flowcharts. http://publicationethics.org/resources/flowcharts. Accessed 27 May 2013

19. Noyori R, Richmond JP (2013) Ethical conduct in chemical research and publishing. Adv Synth Catal 355:3-8. doi:10.1002/ adsc. 201201128

20. Morris SE (2008) Authorship dilemmas for research higher degree students. Refereed proceedings of the 2008 quality in postgraduate research conference, 17-18 April, pp 43-53

21. The University of Sydney (2013) Plagiarism and academic honesty. http://www.library.usyd.edu.au/elearning/learn/plagiarism/ index.php. Accessed 12 July 2013

22. United States Government (2007) America Competes Act. 121 STAT. 574. Public Law 110-69-Aug. 9, 2007, section 7009

23. National Institutes of Health (NIH) (2009) Update on the requirement for instruction in the responsible conduct of research. http://grants.nih.gov/grants/guide/notice-files/NOT-OD-10-019. html. Accessed 12 July 2013

24. University of Florida (2013) Responsible conduct in research (RCR) training. http://research.ufl.edu/compliance/responsibleconduct-in-research.html. Accessed 12 July 2013

25. Horner J, Minifie FD (2011) Research ethics II: mentoring, collaboration, peer review, and data management and ownership. J Speech Lang Hear Res 54:S330-S345. doi:10.1044/10924388(2010/09-0264 